Original Article

\title{
Phenomenology Of Delirium: A Cross-Sectional Study Among Referred Cases Of Delirium
}

\author{
Verma SK ${ }^{1}$, Pandey AK ${ }^{2}$, Adhikari BR ${ }^{3}$, Mallick L ${ }^{4}$
}

\begin{abstract}
1. Lecturer, Department of Psychiatry, NMC, Biratnagar 2. Additional Prof, Department of Psychiatry, BPKIHS,Dharan 3. Asst. Prof, Department of Psychiatry, BPKIHS, Dharan 4. Assistant Professor, Department of Psychiatry, USTC, Chittagong, Bangladesh
\end{abstract}

E-mail *Corresponding author: vermangmc@gmail.com

\begin{abstract}
Introduction: Studies from developing countries are few, on phenomenology of Delirium, even though it is a common diagnosis among psychiatric referrals. We studied the phenomenology of delirium in a teaching hospital in western region of Nepal by using standard assessment methods. Aim: The aim of the study was to assess the phenomenological characteristics of delirium based on Delirium Rating Scale-Revised-98 (DRS-R98). Methods: All consecutive patients of delirium who were referred to department of psychiatry for assessment were enrolled over a period of 12 months. Socio-demographic variables and other medical information were collected by using standardized data-collection forms developed by the department of Psychiatry. Assessments were based on all available information obtained from the patients, caregivers, medical staff, and medical records. Results and conclusions: A total of 62 cases were studied out of which $83.9 \%$ were male. Mean age of the subjects was 47 years. Mean delirium severity was 21.35 (SD=3.54). Orientation, attention and short term memory was impaired in all of the cases. Long term memory impairment was noted in $98.4 \%$ of cases. Sleep wake cycle disturbance was present in 60 (96.8\%) cases, perceptual abnormalities in 49 (79\%) cases, some form of delusion was present in 19 (30.6\%), lability of affect could be appreciated in 27(43.5\%). Language, thought process abnormalities and impaired visuo-spatial ability was present in 19 (30.6\%), 3 (4.8\%) and $13(21 \%)$ cases respectively.
\end{abstract}

Keywords: Delirium, phenomenology, referral, DRS-R98

\section{INTRODUCTION}

Delirium is a neuropsychiatric syndrome characterized by acute or subacute ${ }^{1}$ decline in both, level of consciousness and cognition. ${ }^{2}$ The term delirium originated from Latin verb deliro - to be crazy, which is taken from de + lira, a furrow (i.e., to go out of the furrow where furrow means a long, narrow, shallow trench made in the ground by a plow ${ }^{3}$ ) and was first used by Celsus, in the first century A.D. to describe mental disorders occurring during fever or head trauma ${ }^{4}$ and literally means, "out of track". It is either state of agitation or excessive somnolence. ${ }^{5}$

Delirium is a complex, and frequently reversible impairment of consciousness, occurring in response to one or more physiological and/or pharmacological insults. It occurs in approximately one in five hospitalized patients ${ }^{6}$ and is independently associated with poor outcomes in the form of functional decline, prolonged hospitalization, increased need for institutional care, and elevated mortality and healthcare costs. Despite its high prevalence, delirium is often under recognized and undertreated because of the complex nature of its symptoms, including their variability and fluctuation over time. ${ }^{7}$

Studies from developing countries are few, even though delirium is a common diagnosis among psychiatric referrals. ${ }^{8,9}$ With this background in mind, we studied the phenomenology of delirium occurring in a large teaching hospital in eastern Nepal by use of standard assessment methods. 


\section{MATERIAL AND METHOD}

Subjects and Design:

This cross-sectional study was carried out at B.P. Koirala Institute of Health Sciences (BPKIHS), Dharan, a multispecialty, tertiarycare, teaching hospital. The Department of Psychiatry provides a 24-hour ConsultationLiaison psychiatry service to all the wards and the emergency services of the hospital. Patients consecutively referred to the Consultation-Liaison and with the diagnosis of Delirium were evaluated by a using the Delirium Rating Scale, Revised-98 (DRSR98). ${ }^{10}$

Socio-demographic variables and other medical information were collected by use of standardized data-collection forms developed by the department of Psychiatry BPKIHS. Assessments were based on all available information obtained from the patients, caregivers, medical staff, and medical records.

\section{Assessment Tools:}

The Delirium Rating Scale, Revised-98 (DRS$R 98)^{10}$ is designed for broad phenomenological assessment of delirium. It is a 16-item scale, with 13 severity and 3 diagnostic items, with high inter-rater reliability, sensitivity, and specificity for detecting delirium in mixed neuropsychiatric and other hospital populations. Each item is rated 0 (Absent/Normal) to 3 (Severe Impairment), with descriptions anchoring each severity level. Severity scale scores range from 0 to 39, with higher scores indicating more severe delirium.

Descriptive analysis was used to determine the severity of symptomatology represented by mean DRS-R98 score.

\section{RESULT}

The total number of cases enrolled was 62 out of which $83.9 \%$ were male. All cases were married and of age group ranging from 23yrs to $88 \mathrm{yrs}$, mean age being $47.61 \mathrm{yrs}$ (SD 14.44)

\section{Phenomenological Profile}

As symptom profile was assessed by using Delirium rating scale-revised-98, the severely involved items were orientation, attention and short term memory; in all the cases studied. Long term memory was impaired in 61 $(98.4 \%)$ cases. Sleep wake cycle disturbance was present in $60(96.8 \%)$ cases, perceptual abnormalities in $49(79 \%)$ cases, some form of

Table 1: Delirium Rating Scale revised 98 scoring

\begin{tabular}{|l|l|l|l|l|l|l|}
\hline Items & $0(\%)$ & $1(\%)$ & $2(\%)$ & $3(\%)$ & not assessed & Impaired (\%) \\
\hline Sleep wake cycle & $2(3.2)$ & $4(6.5)$ & $20(32.3)$ & $36(58.1)$ & 0 & $60(96.8)$ \\
\hline Perception & $13(21.0)$ & $1(1.6)$ & $13(21.0)$ & $35(56.5)$ & 0 & $49(79.0)$ \\
\hline Delusion & $43(69.3)$ & $10(16.1)$ & $3(4.8)$ & $6(9.7)$ & 0 & $19(30.6)$ \\
\hline Lability of affect & $35(56.5)$ & $14(22.6)$ & $13(21.0)$ & $0(0)$ & 0 & $27(43.5)$ \\
\hline Language & $40(64.5)$ & $7(11.3)$ & $5(8.1)$ & $7(11.3)$ & $3(4.8)$ & $19(30.6)$ \\
\hline Thought process & $37(59.7)$ & $1(1.6)$ & $2(3.2)$ & $0(0)$ & $22(35.5)$ & $3(4.8)$ \\
\hline Motor agitation & $6(9.7)$ & $1(1.6)$ & $20(32.3)$ & $35(56.5)$ & 0 & $56(90.3)$ \\
\hline Motor retardation & $58(93.5)$ & $0(0)$ & $2(3.2)$ & $2(3.2)$ & 0 & $4(6.5)$ \\
\hline Orientation & $0(0)$ & $0(0)$ & $12(19.4)$ & $50(80.6)$ & 0 & $62(100)$ \\
\hline Attention & $0(0)$ & $0(0)$ & $6(9.7)$ & $56(90.3)$ & 0 & $62(100)$ \\
\hline Short term memory & $0(0)$ & $0(0)$ & $7(11.3)$ & $55(88.7)$ & 0 & $62(100)$ \\
\hline Long term memory & $1(1.6)$ & $3(4.8)$ & $5(8.1)$ & $53(85.5)$ & 0 & $61(98.4)$ \\
\hline Visiospatial ability & $0(0)$ & $0(0)$ & $3(4.8)$ & $10(16.1)$ & $49(79)$ & $13(21.0)$ \\
\hline
\end{tabular}


delusion was present in 19(30.6\%), lability of affect could be appreciated in 27(43.5\%). Language, thought process abnormalities and impaired visio-spatial ability was present in $19(30.6 \%), \quad 3(4.8 \%)$ and $13(21 \%)$ cases respectively. The item language, thought process and visio-spatial ability was difficult to assess in 3(4.8\%), 22(35.5\%) and $49(79 \%)$ respectively because of uncooperativeness of the patients.

In 56(90.3\%) cases motor agitation was present and only $4(6.5 \%)$ cases had some degree of motor retardation.

In the study the Mean DRS-R98 Severity score was 21.35 (Std. dev-3.54) and range was: 1332. Most of the severe cases rated in the range of 21 to 24 score in DRS-R-98. The score was re-assed on $7^{\text {th }}$ day and mean severity score decreased to 4.79 (Std. dev - 3.339).

\begin{tabular}{|c|c|c|c|c|}
\hline Day & Minimum & Maximum & Mean & $\begin{array}{l}\text { Std. } \\
\text { Dev. }\end{array}$ \\
\hline 0 & 13 & 32 & 21.35 & 3.539 \\
\hline $7^{\text {th }}$ & 0 & 14 & 4.79 & 3.339 \\
\hline
\end{tabular}

\section{DISCUSSION}

Studies including the phenomenology of delirium in Nepal literature could not be found but the studies conducted in various other centers and their findings are tabulated below (table 3). In studies done by Rajlakshmi AK et al $(2013)^{11}$; Grover $S$ et al (2012) ${ }^{12}$; Grover S, Shah R (2012) ${ }^{13}$; and Meghar et al $(2007)^{14}$ in phenomenology of delirium using DRS-R-98, the findings are consistent with the current study in the domain of Sleep wake cycle, Perceptual disturbances, Delusions, Motor agitation, Orientation, Attention, Short term memory, Long term memory, Temporal onset of symptoms, Fluctuation, Physical disorder as compared in the table 3 .

In the domain of Lability of affect and Language, variable results are there in different studies. In Thought process and Visuospatial domain the result are inconsistent because of the agitation and uncooperativeness of the patient and need of physical restrain in the patient.

Motor retardation was detected only in 6.5\% of the cases. As the cases were enrolled after the referral was made from other departments it was likely that hypoactive state was missed and the psychiatry call for it was not made. This could be the reason of less percentage of cases having motor retardation.

In another study conducted by Grover $\mathrm{S}$ et al $(2013)^{15}$ including 321 delirium cases, 99.7\% patient had impaired attention which is consistent with the finding of this study being almost all the cases had impaired attention and $90.3 \%$ rated 3 in the DRS-R-98 in the score range of 0 to 3 .

Similarly $98.8 \%$ cases had impaired orientation in the study of Grover S and in this study all the cases were having impaired orientation and $80.6 \%$ had scored 3. Regarding short term memory, $95.6 \%$ cases were having impaired finding and in this study all the cases could not recall the three items given and $88.7 \%$ scored 3. Regarding long term memory in the study of S Grover $52.6 \%$ cases had impairment but in this study $98.3 \%$ cases had impairment and $85.5 \%$ scoring 3 , where score 3 is on a scale of $0-3$ and 3 represents severe level of impairment in each domain.

In sleep wake cycle, perceptual disturbances and lability of affect, $98.1 \%, 79.4 \%$ and $45.2 \%$ were the impairment which were consistent with this study being $96.8 \%, 79 \%$ and $30.6 \%$ respectively.

In Language $(87.5 \%)$ and thought process abnormality $(84.7 \%)$ the findings are inconsistent with this study as the finding in this study was $30.6 \%$ and $4.8 \%$ respectively. This inconsistent finding could be because of the severity of the illness as language in about $4.8 \%$ of the cases and thought process in 35.5\% cases could not be assessed.

Again observing the motor agitation part in both of the studies, $90.3 \%$ had impairment but the cases having motor retardation were only $6.5 \%$ in this study in contrast to $50.8 \%$ in the study done by Grover S. This could be because of reason explained above. With these findings it can be hypothesized that the other specialty unit made call to psychiatry department when agitation was present in the cases.

In the visuospatial ability, $21 \%$ of the cases had impairment in comparison to the study of S Grover in which $63.2 \%$ had the impairment. Here in $79 \%$ cases the visuospatial ability could not be assessed because of the agitation and requirement of restrain to the patient. 
Table 3: Comparison of various study findings with current study findings in percentage

\begin{tabular}{|c|c|c|c|c|c|c|}
\hline & $\begin{array}{l}\text { Rajlaxmi } \\
\text { AK et al11 } \\
(2013) \\
\text { N-84 }\end{array}$ & $\begin{array}{l}\text { Grover S } \\
\text { et al }{ }^{15} \\
(2013) \\
\text { N-321 } \\
\end{array}$ & $\begin{array}{l}\text { Grover S } \\
\text { et al } \\
(2012)^{12} \\
\text { N-109 }\end{array}$ & $\begin{array}{l}\text { Grover S, } \\
\text { Shah R } \\
(2012)^{13} \\
\text { N-53 }\end{array}$ & $\begin{array}{l}\text { Meghar } \\
\text { et al } \\
(2007)^{14} \\
\text { N-100 } \\
\end{array}$ & $\begin{array}{l}\text { Current } \\
\text { study } \\
\text { N-62 }\end{array}$ \\
\hline Sleep wake cycle & 100 & 98.1 & 97.2 & 100 & 97 & 96.8 \\
\hline $\begin{array}{l}\text { Perceptual } \\
\text { disturbances }\end{array}$ & 80.95 & 79.4 & 78.9 & 81.2 & 50 & 79 \\
\hline Delusions & 60.71 & 45.2 & 35.8 & 20.7 & 31 & 30.2 \\
\hline Lability of affect & 94.04 & 85.7 & 62.4 & 83 & 53 & 43.5 \\
\hline Language & 92.85 & 87.5 & 79.8 & 81.1 & 57 & 30.6 \\
\hline $\begin{array}{l}\text { Thought process } \\
\text { abnormality }\end{array}$ & 76.19 & 84.7 & 74.3 & 79.2 & 54 & 4.8 \\
\hline Motor agitation & 86.90 & 90.3 & 89 & 94.3 & 62 & 90.3 \\
\hline Motor retardation & 53.57 & 50.8 & 32.1 & 34 & 62 & 6.5 \\
\hline Orientation & 98.80 & 98.8 & 95.4 & 100 & 76 & 100 \\
\hline Attention & 98.80 & 99.7 & 97.2 & 100 & 97 & 100 \\
\hline Short term memory & 97.61 & 95.6 & 91.8 & 98.6 & 88 & 100 \\
\hline Long term memory & 48.80 & 52.6 & 65.1 & 94.6 & 89 & 98.4 \\
\hline Visuospatial ability & 76.19 & 63.2 & 63.3 & 93.1 & 87 & 21 \\
\hline $\begin{array}{l}\text { Temporal onset of } \\
\text { symptoms }\end{array}$ & 100 & 100 & 100 & 100 & - & 100 \\
\hline Fluctuation & 100 & 97.8 & 92.7 & 100 & - & 100 \\
\hline Physical disorder & 100 & 100 & 100 & 100 & - & 100 \\
\hline
\end{tabular}

\section{SUMMARY AND CONCLUSION}

This study shows that most of the cases included were male with average age of 47yrs. In DRS-R-98 orientation, attention and short term memory was impaired in all the cases. Long term memory was impaired in about $98 \%$ of the cases. Sleep wake cycle disturbances and motor agitation was the common finding in the cases.
Motor retardation which is present in hypoactive delirium was found in only $6.5 \%$ of cases which was less than the finding of other studies. It was difficult to assess the thought process and visiospatial ability in more than one third cases because of the severity of the illness and severe motor agitation in more than half of study population, in DRS-R-98. 


\section{LIMITATION}

As sample size was small, the findings could not be generalized. Before evaluation of the patient by researcher team, medication may had been prescribed which could have altered the presentation during evaluation. As the disease course is fluctuating the actual state of the patient might have been missed as it was a cross-sectional study even though adequate information was tried to collect from patients, care taker and nursing staff. Exact thought process was difficult to assess because of marked agitation and lack of effective bilateral communication.

\section{REFERENCE}

1. Meagher D, Trzepacz P, editors. New oxford textbook of psychiatry. 2nd ed. Oxford university press. 2009.

2. Sadock BJ, Sadock VA, Ruiz P, editors. Kaplan \& Sadock's Comprehensive Textbook of Psychiatry. 9th ed. Philadelphia, USA: Lippincott Williams and Wilkins. 2009. 3.

Oxford dictionaries.com/definition/English/plough 4. Chadwick J, Mann MN. The Medical Works of Hippocrates. Oxford: Blackwell; 1950.

5. Lipowski ZJ. Delirium: how its concept has developed. International Psychogeriatrics 1991; 3(2): 115-120.

6. Siddiqi N; House AO; Holmes JD: Occurrence and outcome of delirium in medical inpatients: a systematic literature review. Age Ageing 2006; 35:350-364

7. Trzepacz PT; Meagher DJ; Leonard M: Delirium, in: Textbook of Psychosomatic Medicine, 2nd Edition. Edited by Levenson JL. Washington, DC, American Psychiatric Press, Inc., 2010

8. Grover S; Subodh BN; Avasthi A et al: Prevalence and clinical profile of delirium: a study from a tertiary-care hospital in north India. General Hosp Psychiatry 2009; 31:25-29 9. Avasthi A; Sharan P; Kulhara $\mathrm{P}$ et al: Psychiatric profiles in medical-surgical populations: need for a focused approach to consultation-liaison psychiatry in developing countries. Indian J Psychiatry 1998; 40:224-230

10. Trzepacz PT; Mittal D; Torres $\mathrm{R}$ et al: Validation of the Delirium Rating Scale, Revised 198: comparison with the Delirium Rating Scale and the Cognitive Test for
Delirium. J Neuropsychiatry Clin Neurosci 2001; 13:229-241

11. Rajlakshmi AK, Mattoo SR, Grover S. Relationship between cognitive and noncognitive symptoms of delirium. Asian Journal of Psychiatry 2013; April 6(2): 106-112. 12. Grover S, Kate N, Agarwal M, Mattoo SK, Avasthi A, Malhotra S, Kulhara P, Chakrabarti S, Basu D. Delirium in elderly people: a study of a psychiatric liaison service in north India. International Psychogeriatrics 2012; 24(1): 117127.

13. Grover S, Shah R. Perceptions among primary caregivers about the etiology of delirium: a study from a tertiary care centre in India. Afr j psychiatry 2012; 15: 193-195.

14. Meagher DJ, Moran M, Raju B, Gibbons D, Donnelly S, Saunders J, Trzepacz PT. Phenomenology of delirium. BJP 2007; 190, 135-141.

15. Grover S, Agarwal M, Sharma A, Mattoo SK, Avasthi A, Chakrabarti S, Malhotra S, Kulhara P, Basu D. Symptoms and Aetiology of Delirium: A Comparison of Elderly and Adult Patients. East Asian Arch Psychiatry 2013;23:56-64 Original Article. 